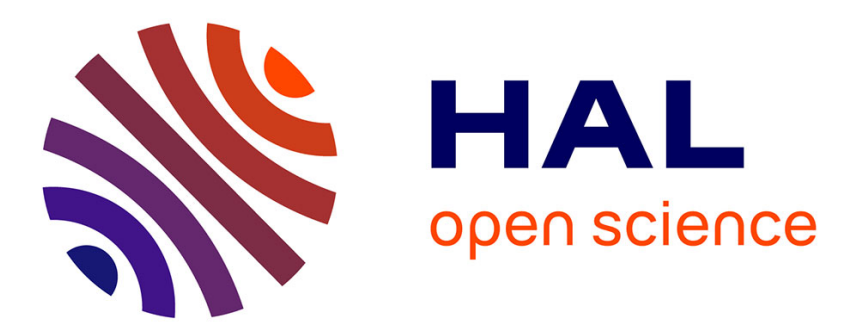

\title{
Visibility analysis of glaciers on steep slopes in the european alps using TERRASAR-X/PAZ data
}

Suvrat Kaushik, Yajing Yan, Ludovic Ravanel, Florence Magnin, Emmanuel Trouvé

\section{- To cite this version:}

Suvrat Kaushik, Yajing Yan, Ludovic Ravanel, Florence Magnin, Emmanuel Trouvé. Visibility analysis of glaciers on steep slopes in the european alps using TERRASAR-X/PAZ data. International Geoscience and Remote Sensing Symposium, Jul 2021, Online, Belgium. pp.5505-5508. hal-03260817

\section{HAL Id: hal-03260817 https://hal.science/hal-03260817}

Submitted on 15 Jun 2021

HAL is a multi-disciplinary open access archive for the deposit and dissemination of scientific research documents, whether they are published or not. The documents may come from teaching and research institutions in France or abroad, or from public or private research centers.
L'archive ouverte pluridisciplinaire HAL, est destinée au dépôt et à la diffusion de documents scientifiques de niveau recherche, publiés ou non, émanant des établissements d'enseignement et de recherche français ou étrangers, des laboratoires publics ou privés. 


\title{
VISIBILITY ANALYSIS OF GLACIERS ON STEEP SLOPES IN THE EUROPEAN ALPS USING TERRASAR-X/PAZ DATA
}

\author{
Suvat Kaushik ${ }^{1,2}$, Yajing Yan ${ }^{1}$, Ludovic Ravanel ${ }^{2}$, Florence Magnin $^{2}$, Emmanuel Trouvé $^{1}$ \\ 1. LISTIC, Université Savoie Mont Blanc, Annecy, France \\ 2. EDYTEM, CNRS - Université Savoie Mont Blanc, Le Bourget du Lac, France
}

\begin{abstract}
This paper focuses on the visibility of glacier surfaces in the Mont Blanc Massif (Western European Alps) on TerraSAR$\mathrm{X} / \mathrm{PAZ}$ images and the identification of geometric distortions (GDs) based on the SAR acquisition geometry. Small glaciers which exist in complex topographies like steep slopes are most prone to GDs. We built a visibility map for both ascending/descending orbits by utilizing previously documented algorithms like the R-Index (RI) and the Layover Shadow (LS) simulations, combined with an analysis of the angle between the steepest slope direction (SSD) and line of sight (LOS) vectors. The visibility map allows us to identify glaciers on steeper slopes which should be considered for further analysis using TerraSAR-X/PAZ images.
\end{abstract}

Index Terms - Geometric distortions, SAR visibility, TerraSAR-X/PAZ, slope glaciers, Mont Blanc Massif

\section{INTRODUCTION}

The immense potential of satellite observations in the fields of glaciology, geohazards monitoring and glacier dynamics is well known to the scientific community. Availability of high resolution spatial and temporal satellite data in hazardous and arduous mountain environment makes them an exciting alternative to field observations [1]. The all-weather all-day capability of Synthetic Aperture Radar (SAR) images gives them an advantage over optical datasets [2]. As a result, recent years have seen the launch of an increasing number of SAR missions with different satellite characteristics. TerraSAR$\mathrm{X}$ launched by the German Aerospace Centre and the Spanish Earth observation satellite PAZ are two of the more recent examples. However, unlike optical sensors, SAR images come with more complex acquisition geometry. SAR systems have a side-looking geometry; hence every target located on Earth being observed by the radar is mapped in the slant range domain. This induces a slope-dependant resolution in the ground range which results in well-known geometric distortion effects, especially in hilly regions. This makes SAR data challenging to interpret in areas of strong relief where the small and poorly understood glaciers are commonly located.
In the past decades, several approaches have been proposed to simulate SAR distortions [3],[1],[4]. In our study, we combined different methodologies to prepare a visibility map which incorporates all types of geometric distortions. Defining strict thresholds for classifying an area as visible or suffering from GDs can lead to uncertainties and over/underestimation of useful areas. Hence, it is crucial to perform a joint analysis of different criteria to finalize the visibility maps. In this study, we propose a vector analysis to take also the visibility of the displacement in the LOS direction into account. The results allows us to identify slope glaciers in the Mont Blanc Massif from our glacier inventory which can be monitored efficiently using TerraSAR-X/PAZ images. The resulting visibility map is essential for future researchers attempting the exploitation of TerraSAR-X/PAZ data for investigation in the Mont Blanc Massif (Western European Alps) especially in the steep slopes.

\section{GEOMETRIC DISTORTION BRIEF OVERVIEW}

The three types of common distortions seen in SAR data sets are foreshortening, layover and shadow. Foreshortening occurs for slopes facing the SAR sensor, where the local slope angle $\phi$ is smaller than the local incidence angle (LIA) of the radar wave. This results in a compression of pixels in the ground range and such slopes are imaged at a worse resolution with brighter reflectivity. When the slope angle equals the incidence angle, the worst conditions occur where slopes are imaged in a unique pixel irrespective of its actual areal extent. Moreover, if the slope inclination exceeds the incidence angle, the 'active' layover effect is seen in a SAR image where the top and bottom of a slope are inverted. Because the effects of layover extend beyond the slope itself, two other types of layover are known, 'near passive' and 'far passive' (Figure 1). For slopes facing away from the SAR sensor if the local terrain slope exceeds the LIA, the local topography prevents the radar beam from illuminating the slope, resulting in a dark region called 'active shadow'. At the end of an active shadow region, where the radar beams cannot reach the slope, a 'passive shadow' region appears as seen in Fig. 1. A more detailed discussion on layover and shadow regions and their interactions can be found in [3]. 


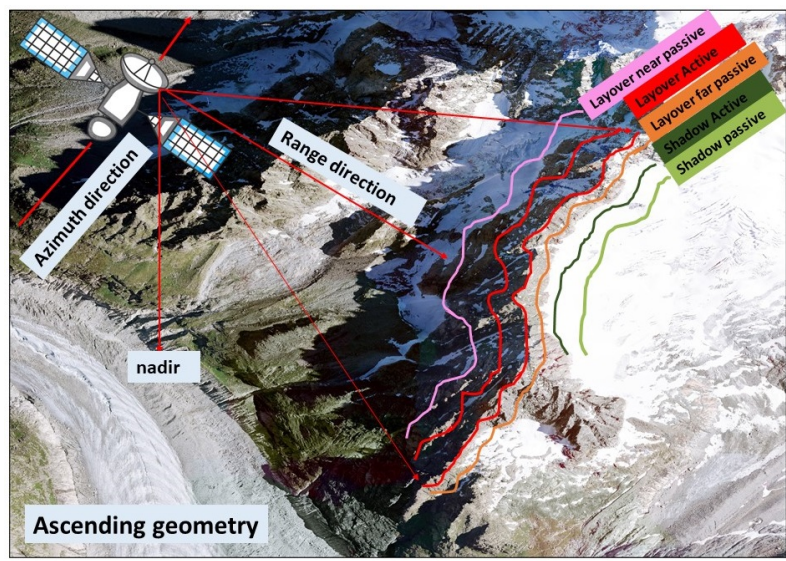

(a) Orthophoto (IGN)

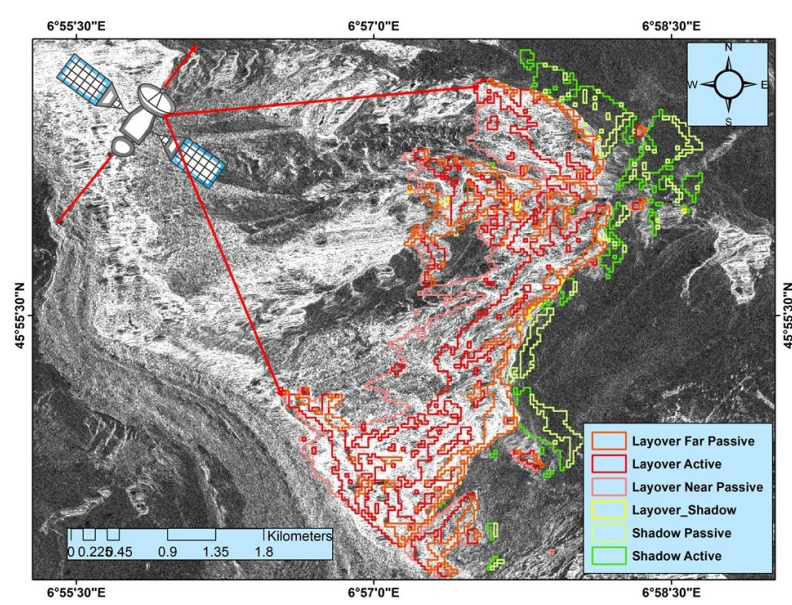

(b) PAZ orthorectified image

Fig. 1. Geometric distortions illustrated on the side of the Mer-de-Glace glacier, Mont Blanc Massif.

\section{METHODOLOGY}

To use SAR images to monitor steep slope glaciers, we need first to check their visibility in ascending or descending images according to their slope and aspect. Then we also need to compare the main flow direction with the SAR Line of Sight (LOS) in order to evaluate if the displacement can be measured in the range direction.

\subsection{R- Index (RI)}

In [1], the authors proposed the R-Index (RI), which effectively integrates the effects of local topography along with satellite acquisition parameters to estimate geometric effects on SAR images. The equation for the RI is given as:

$$
R_{\text {index }}=-\sin \left[\phi \times \sin \left(\alpha_{a}\right)\right]-\sin (\theta)
$$

where, $\phi$ is the slope angle, $\alpha_{a}$ is the corrected aspect according to the satellite orbit and $\theta$ is the incidence angle.
The values for the RI range from -1 to +1 with negative values indicating an unfavourable slope with active layover effects (for slopes facing the sensor with $\phi$ larger than $\theta$ ). Areas of foreshortening show RI values greater than 0 up to a value of $\sin (\theta)$, the latter represents the value taken by the RI for flat terrains where $\phi=0$. This value can be considered as a threshold to differentiate between areas of excellent visibility from the foreshortening regions. For the TerraSAR$\mathrm{X} / \mathrm{PAZ}$ data used for this study on the Mont Blanc Massif (cf. 1), $\theta=37.8^{\circ}$ (descending) and $\theta=44.5^{\circ}$ (ascending) the threshold equals 0.61 and 0.70 respectively. Values closer to zero indicates slopes with intense pixel compression up until a value of 0.30 (descending) and 0.33 (ascending), after which foreshortening effects are gradually minimized. We define this as a threshold for problematic foreshortening and suggest areas above this threshold to be considered as visible with some difficulty. However, as an obvious limitation, the R-Index can only identify areas of 'active layover' and foreshortening regions based on good terrain visibility, but fails to address regions of 'passive layover' and shadows (both active and passive). To overcome this limitation of RI, [5] proposed a combination of the layover and shadow (LS) mask with the R-Index. Layover (active, near passive and far passive) and Shadow (active and passive) (LS) areas were mapped (Fig. 1) using the methodology proposed by [3]. A combined map of the RI and LS simulations is a good indicator of the areas which suffer from all types of geometric distortions (Fig. 3).

\subsection{Vector analysis of LOS displacement visibility}

To complement the results of the RI, a vector analysis of the LOS and the steepest slope direction (SSD) vectors was performed. The SSD vector is important since we assumed the flow of slope glaciers to be along the direction of the maximum slope. Visibility, in this case, will be defined by the angle between the LOS and the SSD vectors. LOS unit vector, with components for ascending $\left(\mu_{a}\right)$ or descending $\left(\mu_{d}\right)$ orbits can be written as:

$$
\mu_{L O S}=\left[\begin{array}{l}
R_{E} \\
R_{N} \\
R_{Z}
\end{array}\right]=\left[\begin{array}{c}
-\sin \theta \cos \alpha_{s} \\
\sin \theta \sin \alpha_{s} \\
\cos \theta
\end{array}\right]
$$

where $\alpha_{s}$ is the angle between the azimuth and North direction. For the TerrSAR-X/PAZ data acquired over the study region, the values of $\alpha_{s}=-10^{\circ}$ and $\theta_{a}=43.35^{\circ}-45.50^{\circ}$ for ascending orbits and $\alpha_{s}=180^{\circ}+10$ and $\theta_{d}=35.96^{\circ}-38.54^{\circ}$ for descending orbits. Accordingly, the components of ascending and descending unit LOS vectors can be computed as:

$$
\mu_{a}=\left[\begin{array}{c}
-0.696 \\
-0.112 \\
0.709
\end{array}\right], \mu_{d}=\left[\begin{array}{c}
0.602 \\
-0.106 \\
0.789
\end{array}\right]
$$


The SSD unit vector, along the upward/downward slope direction and assumed positive upward can be defined as:

$$
\mu_{S S D}=\left[\begin{array}{c}
-\sin \alpha \cos \phi \\
-\cos \alpha \cos \phi \\
\sin \phi
\end{array}\right]
$$

The angle between the LOS and SSD vectors can hence be given by:

$$
\delta=\cos ^{-1}\left[\mu_{L O S} \cdot \mu_{S S D}\right]
$$

\section{RESULTS AND DISCUSSION}

\subsection{Datasets}

The datasets used in this study are summarized in Table 1.

\begin{tabular}{||ccc||}
\hline Data & Resolution (m) & Acquisition \\
\hline \hline ALOS World 3D DEM & 30 & $31 / 03 / 2015$ \\
\hline PAZ SAR (Asc.) & $6 \times 6$ & $21 / 05 / 2020$ \\
PAZ SAR (Desc.) & $6 \times 6$ & $30 / 05 / 2020$ \\
\hline Orthophotos (IGN) & 0.2 & 2015 \\
Pleaides 1B PAN & 0.5 & $25 / 08 / 2019$ \\
\hline
\end{tabular}

Table 1. Datasets used for the study.

\subsection{Joint analysis of R-Index and vector angle $(\delta)$}

Fig. 2 shows the vector angles and the RI for the ascending orbits, with varying terrain aspects and slopes. A first conclusion is that slopes with negative and low RI values have high $\delta$ angles and as terrain slopes become perpendicular to the LOS direction $\delta$ approaches $90^{\circ}$ and R-Index equals 0 . This worst condition occurs when terrain slope equals the incidence angle of the satellite $(\phi=\theta)$. Higher RI values correspond to low $\delta$ angles indicating a parallel orientation of the slopes and the best viewing geometry. Also for both criteria, a generalized rule is that for the ascending orbits, with constant slope angles, the East, North-East and South-East aspects show higher RI and lower $\delta$ values, compared to North and South aspects. West, North-West, and South-West aspects generally show low RI and high $\delta$ values indicating regions of prominent layover or foreshortening. However, one can observe that RI values can be higher than a RI visibility threshold ( 0.3 for instance) for North/North-West and South/SouthWest aspects, but for the same areas the $\delta$ values can be large (above $70^{\circ}$ ). This suggests that even in areas of good visibility it can be difficult to measure displacement in the LOS direction along the SSD. All these conclusions are opposite for the descending orbits.

\subsection{Visibility map of MBM for PAZ/TerraSAR-X}

Areas that suffer from geometric distortions and good visibility areas for TerraSAR-X/PAZ ascending and descending im-

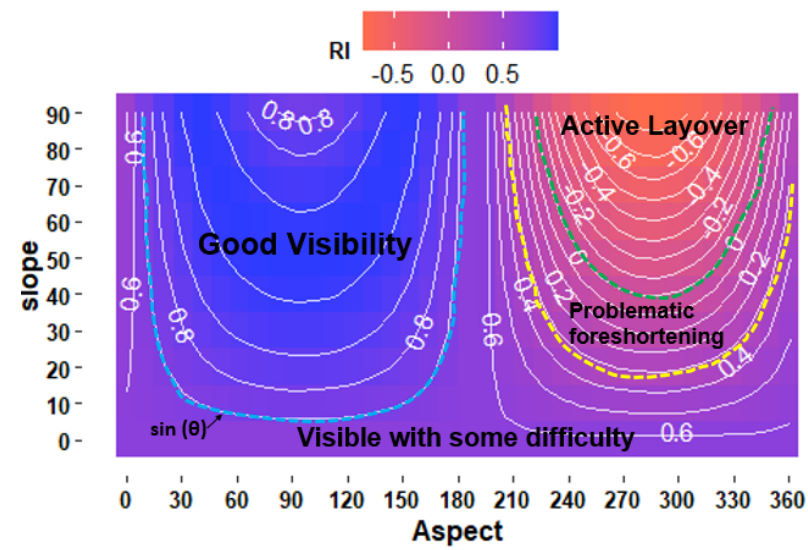

(a) R-Index

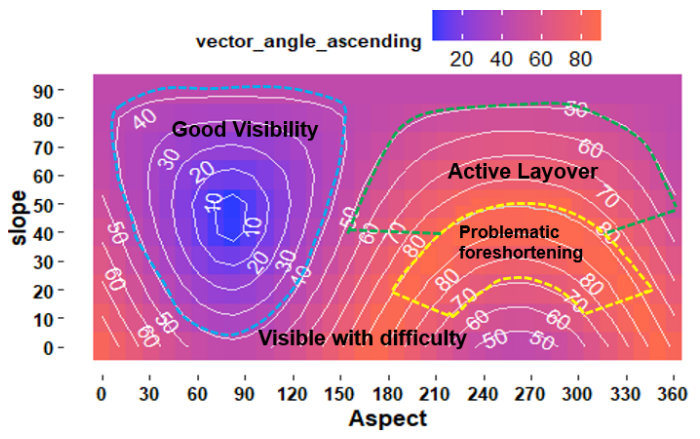

(b) Angle between the LOS and SSD vectors

Fig. 2. (a) R-Index and $\delta$ angle with respect to terrain slope $(\phi)$ and aspect $(\alpha)$ for PAZ ascending images with incidence angle $\theta=44.5^{\circ}$.

ages were mapped for the Mont Blanc Massif. For ascending images, $73.5 \%$ of the total area could be considered as having excellent or good visibility, while $26.5 \%$ of areas suffer from geometric distortion (Fig. 3). Similarly, $72 \%$ of the areas are visible, and $28 \%$ of areas suffer from geometric distortions for the descending images. $53.8 \%$ of the common areas between the two images is visible, while only $8 \%$ of the areas suffer from distortions in both orbits. This underlines the potential of SAR datasets even in mountainous regions as more than $92 \%$ of the study region is visible from either ascending or descending orbits of TerraSAR-X/PAZ.

\subsection{Visibility of glaciers in the Mont Blanc Massif}

This study aims to assess the visibility of glaciers on steep slopes in TerraSAR-X/PAZ images. For this, it was essential to have an inventory of different glacier types, at a very high resolution. Since this type of dataset is not freely available, we decided to prepare our database by manually digitizing glacier boundaries on very high resolution orthophotos $(20 \mathrm{~cm}$ resolution) and Pleiades stereo images $(50 \mathrm{~cm}$ resolution). Different glacier types were defined and accurately delineated. We classified cirque glaciers, slope glaciers, slope glaciers with hanging front $(\mathrm{HG})$, slope glaciers connected to 


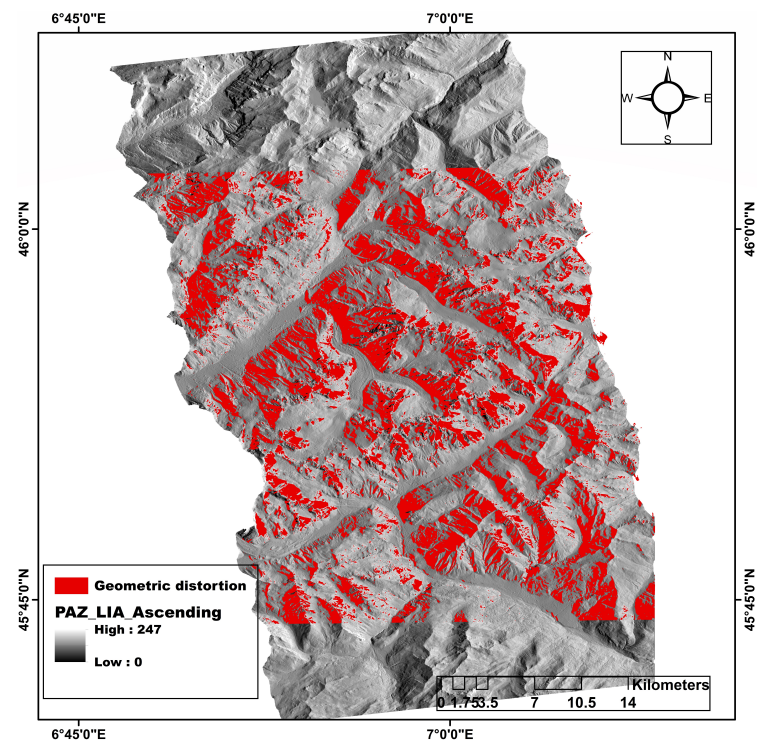

Fig. 3. Visibility map for TerraSAR-X/PAZ ascending images

other glacier systems (CGS) in one class as these glacier types are commonly found on steep slopes.

We classified a glacier as 'visible' if $50 \%$ or more area of the glacier is visible in the considered SAR image without any geometric distortion, and 'not visible' for analysis otherwise. We found that out of the 138 steep slope glaciers only 25 glaciers showed poor visibility in the descending orbit data, while only 17 glaciers out of 111 glaciers were not visible in the ascending pass. The ambiguity in the total number of glaciers analysed by the two orbits is a result of the differences in scene coverage. All glaciers are visible if we consider images from either the ascending or descending passes (Fig. 4).

\section{CONCLUSIONS}

The first part of the study shows the effectiveness of existing methodologies for assessing areas of good visibility and geometric distortions. We prepared a TerraSAR-X/PAZ visibility map for the Mont Blanc Massif using a combination of RI and LS maps and then cross-validated our results from the vectorial analysis of LOS and SSD vectors. The results show that almost a quarter of the total area in individual orbits suffer from geometric distortions which might prove difficult for any further useful analysis. However, most of the total area is visible if we use data from both the ascending and descending orbits. A final analysis of the glaciers visible on steep slopes suggests that most of the glaciers show good visibility even if data from only one orbit is available, and all glaciers are visible if both orbits of the satellite are utilized for analysis. The results from our analysis provide a ready-to-use guide for the Mont Blanc Massif for image analysts and glaciologists for further exploitation of TerraSAR-X/PAZ data.

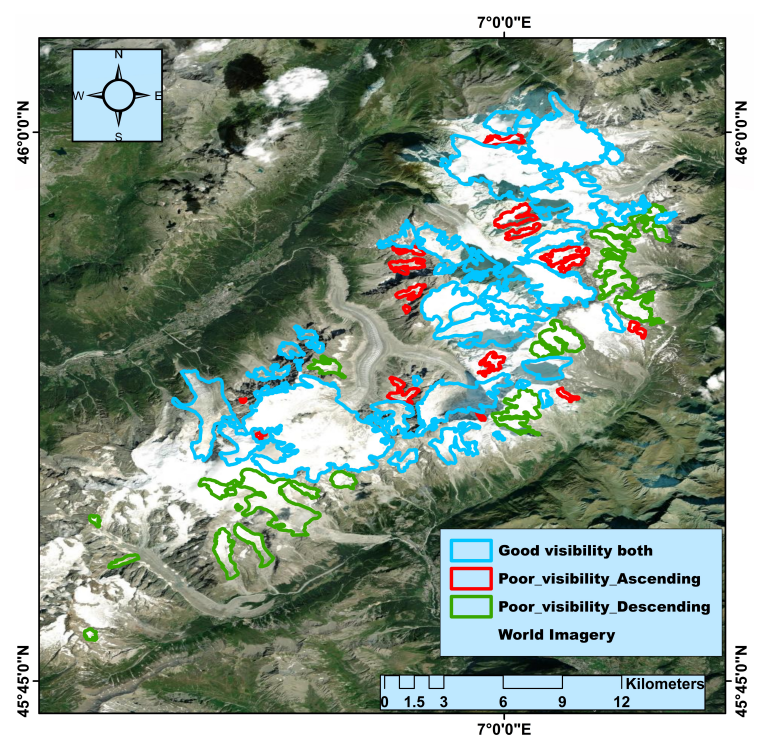

Fig. 4. Glacier visibility analysis in the Mont Blanc Massif for TerraSAR-X/PAZ images.

\section{Acknowledgement}

The authors would also like to thank the German Aerospace Agency (DLR) for the TerraSARX images (Project MTH0232) and the Spanish Instituto Nacional de Tecnica Aerospacial (INTA) for the PAZ images (Project AO-001-051).

\section{REFERENCES}

[1] D Notti, C Meisina, F Zucca, and A Colombo, "Models to predict persistent scatterers data distribution and their capacity to register movement along the slope," in Fringe 2011 Workshop, 2011, pp. 19-23.

[2] Carlo Colesanti and Janusz Wasowski, "Investigating landslides with space-borne synthetic aperture radar (sar) interferometry," Engineering geology, vol. 88, no. 3-4, pp. 173-199, 2006.

[3] Walter G Kropatsch and Dieter Strobl, "The generation of sar layover and shadow maps from digital elevation models," IEEE Transactions on Geoscience and Remote Sensing, vol. 28, no. 1, pp. 98-107, 1990.

[4] Leonardo Cascini, Gianfranco Fornaro, and Dario Peduto, "Advanced low-and full-resolution dinsar map generation for slowmoving landslide analysis at different scales," Engineering $\mathrm{Ge}$ ology, vol. 112, no. 1-4, pp. 29-42, 2010.

[5] Francesca Cigna, Luke B Bateson, Colm J Jordan, and Claire Dashwood, "Simulating sar geometric distortions and predicting persistent scatterer densities for ers-1/2 and envisat c-band sar and insar applications: Nationwide feasibility assessment to monitor the landmass of great britain with sar imagery," Remote Sensing of Environment, vol. 152, pp. 441-466, 2014. 